\title{
Updraft Constraints on Entrainment: Insights from Amazonian Deep Convection
}

\author{
UsAma M. ANBER AND SCOTT E. GIANGRANDE \\ Brookhaven National Laboratory, Upton, New York \\ LEO J. DONNER \\ NOAA/Geophysical Fluid Dynamics Laboratory, Princeton, New Jersey \\ MiCHAEL P. JENSEN \\ Brookhaven National Laboratory, Upton, New York
}

(Manuscript received 8 August 2018, in final form 10 May 2019)

\begin{abstract}
Mixing of environmental air into clouds, or entrainment, has been identified as a major contributor to erroneous climate predictions made by modern comprehensive climate and numerical weather prediction models. Despite receiving extensive attention, the ad hoc treatment of this convective-scale process in global models remains poor. On the other hand, while limited-area high-resolution nonhydrostatic models can directly resolve entrainment, their sensitivity to model resolution, especially with the lack of benchmark mass flux observations, limits their applicability. Here, the dataset from the Observations and Modeling of the Green Ocean Amazon (GoAmazon2014/5) campaign focusing on radar retrievals of convective updraft vertical velocities is used with the aid of cloud-resolving model simulations of four deep convective events over the Amazon to provide insights into entrainment. Entrainment and detrainment are diagnosed from the model simulations by applying the mass continuity equation over cloud volumes, in which grid cells are identified by some thresholds of updraft vertical velocity and cloud condensates, and accounting for the sources and sinks of the air mass. Entrainment is then defined as the environmental air intruding into convective cores causing cloud volume to shrink, while detrainment is defined as cloudy grid cells departing the convective core and causing cloud volume to expand. It is found that the diagnosed entrainment from the simulated convective events is strongly correlated to the inverse of the updraft vertical velocities in convective cores, which enables a more robust estimation of the mixing time scale. This highlights the need for improved observational capabilities for sampling updraft velocities across diverse geographic and cloud conditions. Evaluation of a number of assumptions used to represent entrainment in parameterization schemes is also presented, as contrasted against the diagnosed one.
\end{abstract}

\section{Introduction}

Modern climate science inferred from global climate models (GCMs), as well as observations, points toward the important influence by cumulus convection on the vertical structure of the atmosphere. Through vertical distribution of heat, moisture, and momentum, cumulus convection determines precipitation and clouds, and largely affects the global energy balance through interaction with the solar and longwave radiation. Stateof the-art climate and numerical weather prediction (NWP) models are still incapable of fully resolving cumulus clouds and related processes. These processes

Corresponding author: Usama Anber, uanber@bnl.gov. need to be incorporated in a statistical fashion through parameterizations in terms of resolved variables, with free parameters adjusted in such a way as to maintain the energy balance at the top of the atmosphere. In doing so the simulated climatic metric will depend on the representation of the subgrid processes. Entrainment has been shown to be the subgrid process to which climate simulations are most sensitive.

For example, some studies (Zhao et al.2009; Park and Bretherton 2009) have shown that tropical land rainfall over the Amazon is severely underestimated when entrainment rate is set to be moderately high, and that decreasing entrainment rate significantly improves the simulated rainfall, though the afternoon peak remains too strong. Overall, land rainfall was shown to 
be more sensitive to entrainment rate than to model resolution, unlike tropical oceanic rainfall, which results, for the most part, from organized clusters of deep convective clouds.

At shorter, intraseasonal, time scales, realistic simulation of the Madden-Julian oscillation (MJO) remains a hurdle in most GCMs. By modifying the convection scheme to have a greater fractional entrainment rate, some models simulate MJO-like disturbances with reasonable spatial and temporal scales (e.g., Bechtold et al. 2008; Kim et al. 2011). It was demonstrated that with greater entrainment rates, convection organization is activated over confined areas featuring a sharper contrast between wet and dry phases. However, this improvement comes at the expense of increasing mean state bias, and carries further implications on the simulated climatology of tropical cyclones (TCs). Kim et al. (2011) report a monotonic behavior for the simulated TC frequency that decreases as the entrainment rate increases. Meanwhile, Zhao et al. (2012), report a nonlinear response in which TC frequency initially increases until reaching a maximum before decreasing at larger values of entrainment. This behavior involves intricate feedbacks between resolved-scale convection and parameterized convective mass flux, reiterating the complex role of entrainment in reducing the mass flux that dries and cools the troposphere and moistens the boundary layer.

Finally, entrainment plays a critical role in the simulated equilibrium climate sensitivity (e.g., Stainforth et al. 2005; Rougier et al. 2009; Sanderson et al. 2010; Zelinka et al. 2012; Sherwood et al. 2014; Zhao 2014). In particular, Zhao (2014) conducted perturbed physics experiments with an atmospheric GCM, finding that convective precipitation efficiencies, which changed during global warming, were an important control on cloud radiative properties. The degree to which convective precipitation efficiencies changed during global warming depended on convective entrainment rates and convective microphysics. Varying the entrainment rate thus led to drastically different climate sensitivities as estimated from the response in the top-of-atmosphere (TOA) energy balance, when applying a uniform increase in sea surface temperatures. Dominated by shortwave feedbacks, the model differences appeared to originate from different dynamical regimes, ranging from large-scale ascent to subsidence regions. Although others (Klocke et al. 2011; Zelinka et al. 2012; Sherwood et al. 2014) suggested a bigger role for entrainment mixing in shallow convection, it is plausible that both shallow and deeper clouds are linked through the largescale dynamics of the Hadley and Walker circulations, where entrainment in deep convection affects latent heat release, exhibiting a remote control on regions of stratocumulus and shallow cumulus ( $\mathrm{Su}$ et al. 2014; Donner et al. 2016).

The aforementioned issues in climate models seem to originate from the lack of resolving convective mass flux and the resulting entrainment rate. Limited-area nonhydrostatic models that explicitly resolve convection, however, are widely employed to estimate entrainment and establish relationships with environmental as well as cloud-scale variables (e.g., de Rooy et al. 2013). Here we find that, for deep convection, the most important of these cloud-scale variables is the updraft vertical velocity. The observations and retrievals of updraft vertical velocity, now available from the Observations and Modeling of the Green Ocean Amazon (GoAmazon2014/5) field campaign, prove to be critical to estimate entrainment rates.

This paper is organized as follows. In section 2 we present the observational dataset, the numerical model used to simulate deep convective events in the Amazon, and the diagnostic method to compute entrainment and detrainment from the model simulations. In section 3, we present the entrainment and detrainment profiles of the simulated events, contrast the model-diagnosed entrainment against several assumptions used in parameterization schemes, and constrain the diagnostic entrainment with observations of the in-cloud updraft vertical velocities and estimate the mixing time scale. We summarize the results in section 4.

\section{Methods}

\section{a. Observational dataset}

The data used in this manuscript are from observed convective systems during the two intensive operational periods conducted in the wet (15 February-26 March 2014) and dry (1 September-10 October 2014) seasons near Manaus, Brazil, during the GoAmazon2014/5 experiment (e.g., Martin et al. 2016, 2017; Giangrande et al. 2016).

Derived large-scale forcing data from the GoAmazon2014/5 experiment (Tang et al. 2016, 2001) are used to force the model simulations below. The large-scale vertical velocity and budgets were derived using the $0.5^{\circ} \times 0.5^{\circ}$ European Centre for Medium-Range Weather Forecasts (ECMWF) analysis data, as a first guess, constrained with TOA radiative fluxes from GOES-13 and surface fluxes averaged over the analysis domain (Fig. 1 of Tang et al. 2016) for the variational analysis (VARANAL).

Surface precipitation is derived from the System for the Protection of Amazonia (SIPAM) S-band (10-cm wavelength) radar operated at the center of the 
(a) $U\left(m . s^{-1}\right)$

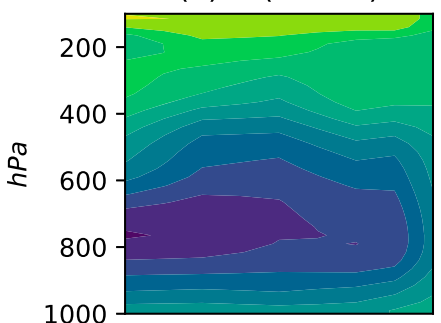

(e) $V\left(m \cdot s^{-1}\right)$

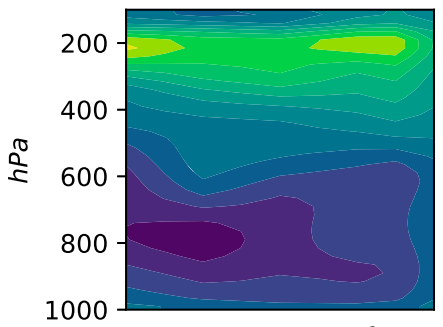

(i) $\omega\left(h P a \cdot h^{-1}\right)$

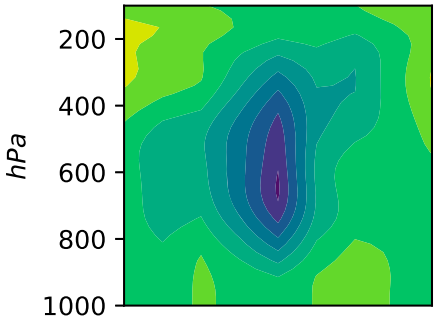

(m) $T_{a d v}\left(K . h^{-1}\right)$

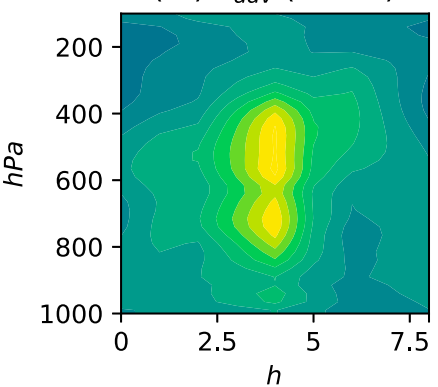

(b)

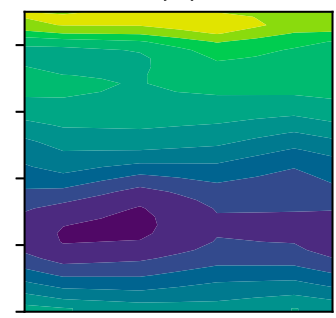

(f)

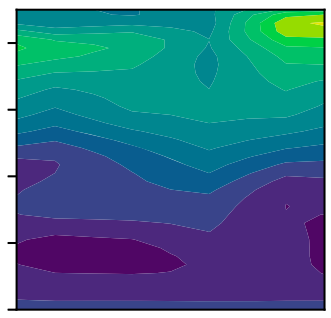

(j)

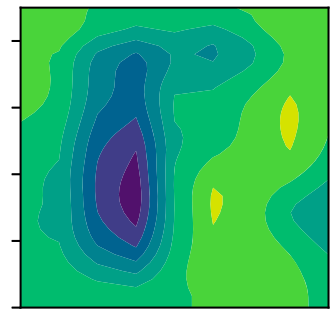

(n)

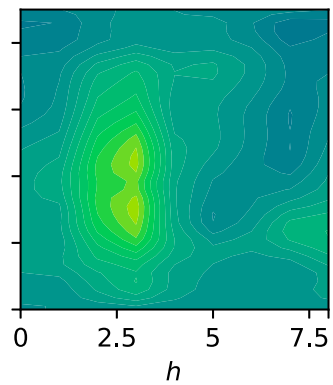

(c)

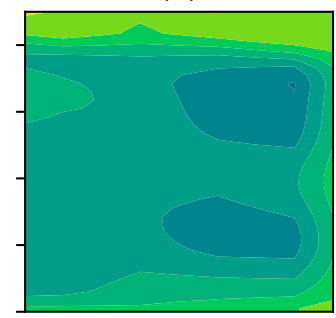

(g)

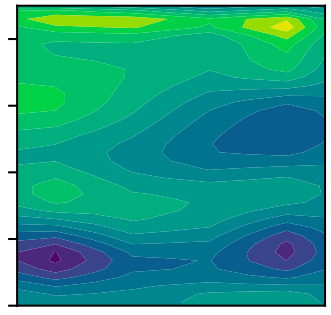

(k)

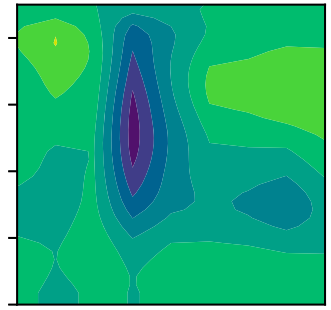

(o)

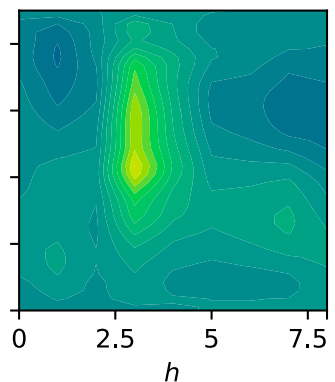

(d)

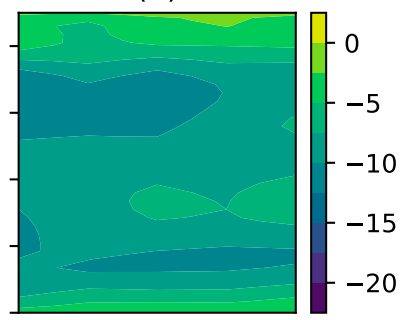

(h)

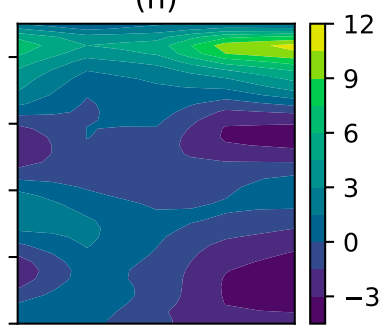

(l)

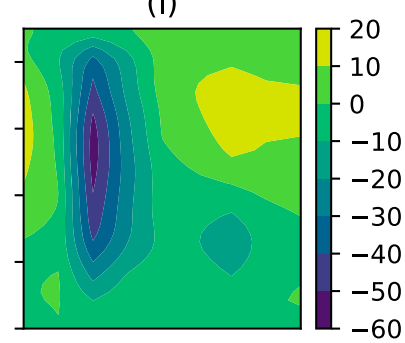

(p)

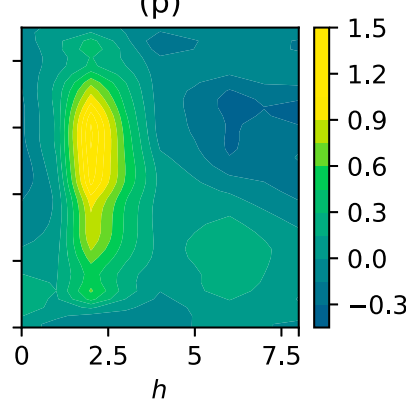

FIG. 1. Observed large-scale forcing of: (a)-(d) horizontal winds $U\left(\mathrm{~m} \mathrm{~s}^{-1}\right)$, (e)-(h) $V\left(\mathrm{~m} \mathrm{~s}^{-1}\right)$, (i)-(l) pressure vertical velocity (hPa h $\left.{ }^{-1}\right)$, and $(\mathrm{m})-(\mathrm{p})$ vertical and horizontal advection of temperature $\left(\mathrm{K} \mathrm{h}^{-1}\right)$ for four selected cases of deep precipitating convection from the GoAmazon 2014/15 campaign on (from left to right) 19 and 20 Mar and 7 and 8 Sep 2014. Horizontal axis is hours since deep convection onset.

GoAmazon2014/5 experiment domain (Ponta Pelada airport). The Atmospheric Radiation Measurement (ARM) 1290-MHz UHF radar wind profiler (RWP) is the primary instrument for estimated convective cloud updraft vertical velocity retrievals (Giangrande et al. 2016).

Surface latent and sensible heat fluxes are derived from the broadband radiometer (Long et al. 1994) and eddy correlation flux measurement system (McCoy et al. 2003) at the ARM Mobile Facility site near Manacapuru and two other Brazilian research sites (see Fig. 1 of Tang et al. 2016).
The derived large-scale forcing and the surface latent and sensible heat fluxes are 3-hourly averaged over the GoAmazon2014/5 experiment domain. In our study, we will focus on four deep convective precipitating events on 19 and 20 March and 7 and 8 September 2014, whose large-scale forcing (horizontal winds, large-scale vertical velocity, and temperature advection) and surface forcing of latent and sensible heat fluxes are shown in Figs. 1 and 2, respectively. A full description of the observational dataset is detailed in Tang et al. (2016). 
(a)

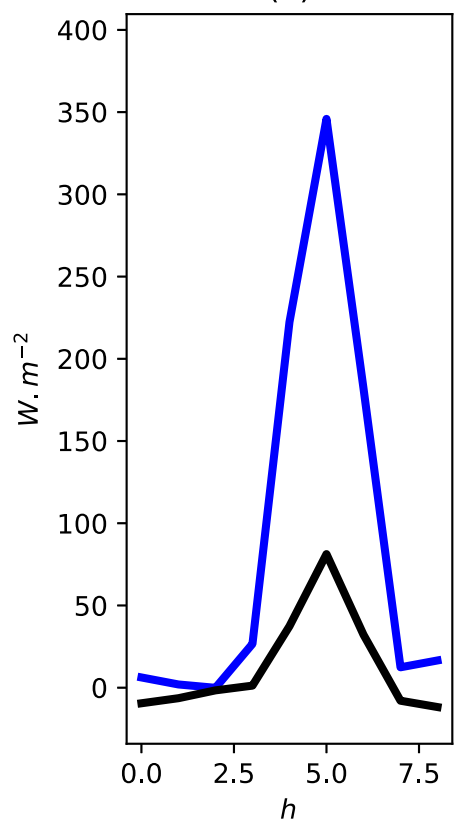

(b)

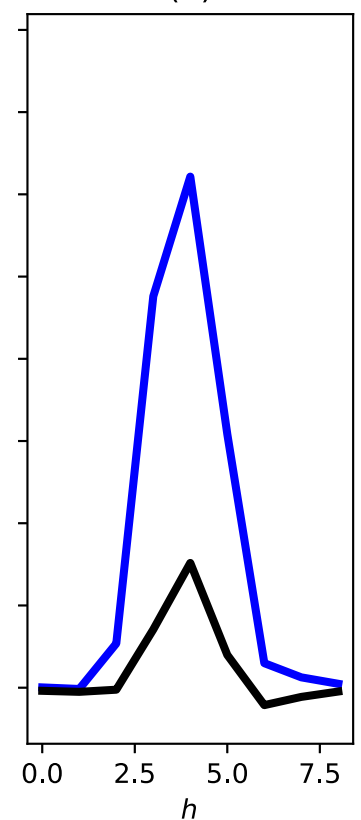

(c)

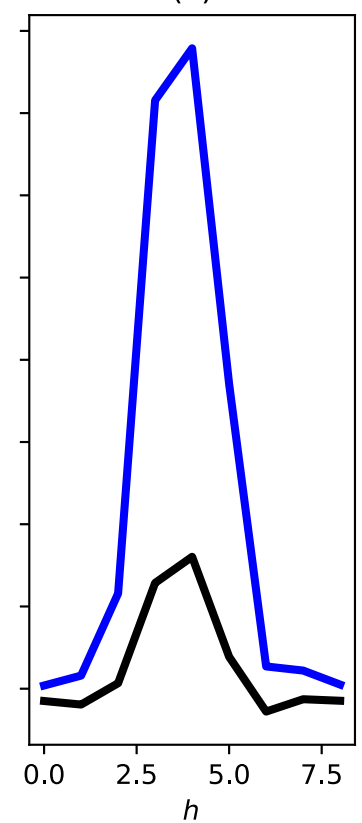

(d)

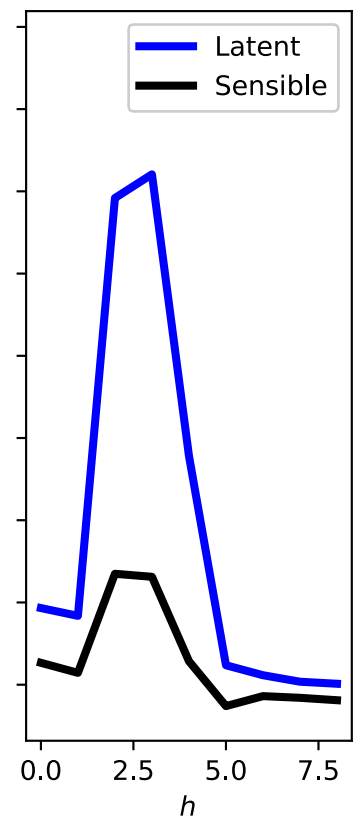

FIG. 2. Derived surface forcing of latent (blue) and sensible (black) heat fluxes ( $\mathrm{W} \mathrm{m}^{-2}$ ) on (a) 19 and (b) $20 \mathrm{Mar}$ and (c) 7 and (d) 8 Sep 2014.

\section{b. Numerical model}

We use the Advanced Research version of the Weather Research and Forecasting (WRF) Model, version 3.3 (Skamarock et al. 2008), at convectivescale resolution to simulate the four events. The model's horizontal subgrid eddies are treated using Smagorinsky first-order closure. The Morrison doublemoment scheme (Morrison et al. 2005) is used for cloud microphysics. The horizontal and vertical advection schemes are fifth and third order, respectively (Skamarock et al. 2008). Moisture and other scalars are advected using a positive-definite scheme (Skamarock et al. 2008). We use the implicit scheme (Klemp et al. 2008) to damp unphysical reflection of vertically propagating gravity waves in the top $5 \mathrm{~km}$ of the numerical grid.

The model is forced with the derived large-scale mean horizontal and vertical wind, temperature and its advection (Fig. 1) and surface latent and sensible heat fluxes (Fig. 2) from the GoAmazon 2014/5 experiment. The model domain-averaged wind and temperature profiles are nudged toward the observed variables over relaxation time scale of $1 \mathrm{~h}$. Simulations were performed with horizontal grid spacing of $1 \mathrm{~km}$. Sensitivity to resolutions of 2000, 500, 200,100, and $50 \mathrm{~m}$ is also discussed. We use 60 vertical levels with 10 levels in the lowest $1 \mathrm{~km}$ and grid spacing gradually increasing to $1.5 \mathrm{~km}$ near the model top $\sim 25 \mathrm{~km}$. The computational domain has $96 \times 96$ horizontal grid points and operates on doubly periodic boundary conditions.

\section{c. Model-diagnosed entrainment and detrainment}

To compute the entrainment and detrainment, we use a diagnostic method as in Romps (2010). We first divide the flow into convective cores (assuming thresholds of cloud condensate and updraft vertical velocity) and environment by defining a Heaviside operator that is takes the value of 1 if it belongs to the former and 0 if it is the later. That is,

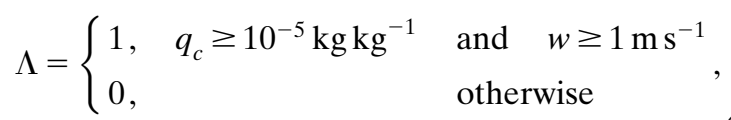

where $q_{c}$ is the cloud condensate mixing ratio of liquid water and ice water.

Conservation of mass of the entire flow proclaim a continuity:

$$
\frac{\partial \rho}{\partial t}+\nabla \cdot(\rho \mathbf{v})=0
$$

where $\rho$ is the air density and $\mathbf{v}=(u, v, w)$ is the velocity vector. Applying the continuity above to the convective cores,

$$
\frac{\partial(\Lambda \rho)}{\partial t}+\nabla \cdot(\Lambda \rho \mathbf{v})=E-D
$$


where $E$ is the source to the left-hand side of Eq. (3) resulting from environmental air $(\Lambda=0)$ entering into convective cores and changing the value to $\Lambda=1$, and $D$ is the sink resulting from convective air departing the core to the environment and changing value to $\Lambda=0$. Therefore, the definition of entrainment and detrainment flows naturally; $E$ is the entrainment and $D$ is the detrainment. That is, we calculate the left-hand side of Eq. (3) integrated over the convective-core volume: when the air mass enters the volume though the cloud boundary, this quantity is positive and designated as entrainment, and when it is negative (air mass leaving the convective-core volume) it is detrainment:

$$
\begin{aligned}
& E=\max \left\{0, \frac{\partial \overline{(\Lambda \rho)}}{\partial t}+\overline{\nabla \cdot(\Lambda \rho \mathbf{v})}\right\}, \\
& D=\max \left\{0,-\frac{\partial \overline{(\Lambda \rho)}}{\partial t}-\overline{\nabla \cdot(\Lambda \rho \mathbf{v})}\right\},
\end{aligned}
$$

where overbars denote the integral over the convective core volume. The left-hand side of Eq. (3) is evaluated numerically using the finite-difference scheme on Arakawa C grid as in Dawe and Austin (2011):

$$
\begin{aligned}
E-D= & \frac{\partial\left[\Lambda \rho_{(k)}\right]}{\partial t}+\rho_{(k)}\left[u_{(i+1, j, k)} W_{x(i+1, j, k)}-u_{(i, j, k)} W_{x(i, j, k)}\right] \\
& +\rho_{(k)}\left[v_{(i, j+1, k)} W_{y(i, j+1, k)}-v_{(i, j, k)} W_{y(i, j, k)}\right] \\
& +\frac{1}{2}\left[\rho_{(k+1)}+\rho_{(k)}\right] w_{(i, j, k+1)} W_{z(i, j, k+1)} \\
& -\frac{1}{2}\left[\rho_{(k)}+\rho_{(k-1)}\right] w_{(i, j, k)} W_{z(i, j, k)}
\end{aligned}
$$

where $\mathbf{W}$ is a unit vector normal to the surface of grid box of convective core, that is, $|\mathbf{W}|=1$, and indices $i, j$, and $k$ denote discretization in the $x, y$, and $z$ directions, respectively. Then an integral over the cloud volume is performed.

Note that quantities $q$ and $w$ defining cloud cores are prognostic variables whose fluxes are calculated by the model's advection scheme, but the quantity $\Lambda \rho \mathbf{v}$ is not. The $\Lambda$ operator is applied after each time step has completed the computation of $q$ and $w$ to determine which grid cell is considered cloud core and which is not (environment). Once cloud cores are defined, if air mass enclosed by the cloud boundary leaves the core to the environment, it is defined as detrainment, and if air mass enters the cores from the environment, it is defined as entrainment. This mass exchange between the core and the environment takes place across the boundary of the cloud cores determines $E$ and $D$. In other words, $D(E)$ is evaluated after the cloud boundary has swept over the grid of an opposite sign, which is equivalent to the expansion (contraction) of the cloud material surface (Dawe and Austin 2011).

\section{Results}

\section{a. Entrainment in Amazonian deep convection}

The model simulated precipitation for the four convective events from 19 and 20 March and 7 and 8 September 2014, shown in Figs. 3a-d, respectively, exhibits an excellent agreement with the observationally derived (VARANAL) precipitation. To compute entrainment and/or detrainment, we first identify convective cores as defined in Eq. (1). Figure 4 shows the time evolution of the simulated convective-core air concentration $\left(\mathrm{kg} \mathrm{m}^{-3}\right)$, with cloud base at about $200 \mathrm{~m}$ and maximum air density attained at lower to middle levels.

Net entrainment, defined as the sum of the sources and sinks $(E-D)$ of the mass conservation applied to convective cores, which represents the change in convective mass flux, as in Eq. (3), averaged over the four events is shown in Fig. 5a. It reaches maxima near the cloud base at about $500 \mathrm{~m}$, indicating maximum entrainment (Fig. 5b) at that level. Negative net entrainment is attained at the mid- and upper troposphere, indicating maximum detrainment there (Fig. 5b). A secondary maximum in net entrainment appears below $4 \mathrm{~km}$, which roughly marks the freezing level. Defining the convective mass flux as $M=\langle\rho \Lambda w\rangle$, where the angle brackets denote horizontal averages, one can then write $\varepsilon=E / M$ and $\delta=D / M$ denoting the entrainment and detrainment rate, respectively, which is the amount of entrained and detrained air per unit distance in the vertical and shown in Fig. 5c. The concept of rate pertains to the bulk-plume theory (Yanai et al. 1973), which idealizes deep convection by raising plumes of clouds. In reality the validity of this concept, especially in tropical deep convection, is not clear as convection tends to cluster over extended areas, and individual plumes are not well defined. Nevertheless, we will adopt this convention here.

Since Eq. (3) is exact, the only approximations made are numerical. Therefore, a serious issue of the modeldiagnosed entrainment arises from the strong dependence on the model's horizontal resolution as noted in Dawe and Austin (2011). Figure 6 shows a monotonic dependence on resolution with as much as an order of magnitude discrepancy between profiles at coarser and finer resolution. This behavior is expected since $D$ and $E$ are accounted for only when the cloud interface sweeps over or retreats from the entire adjacent grid 
(a)

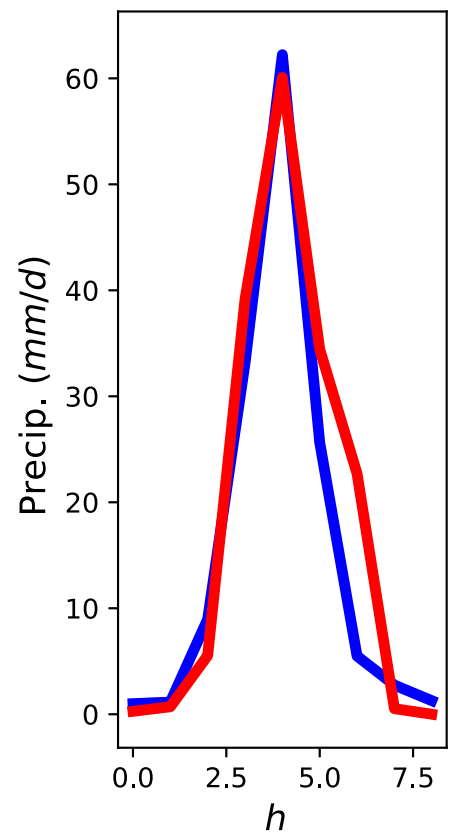

(b)

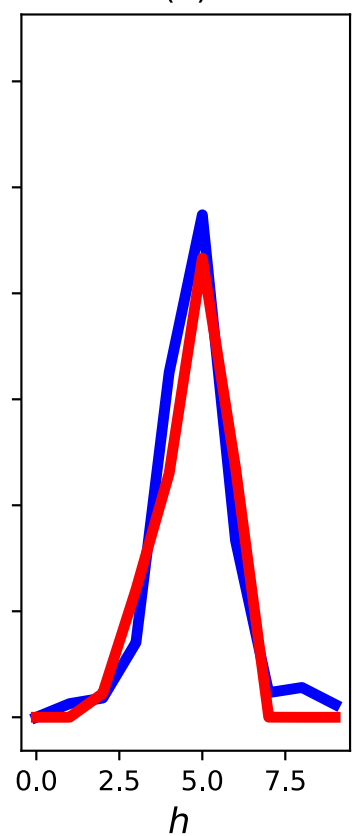

(c)

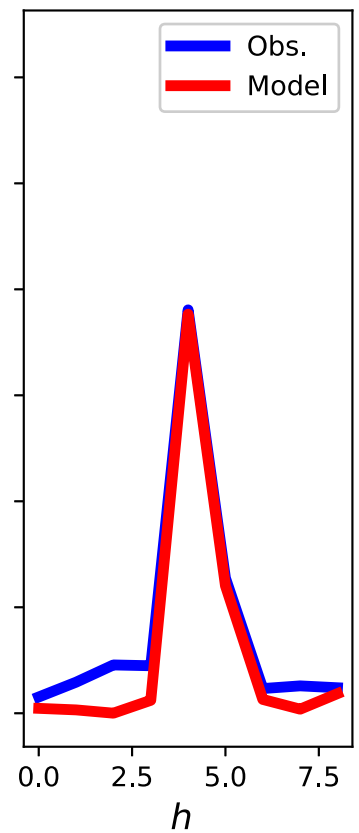

(d)

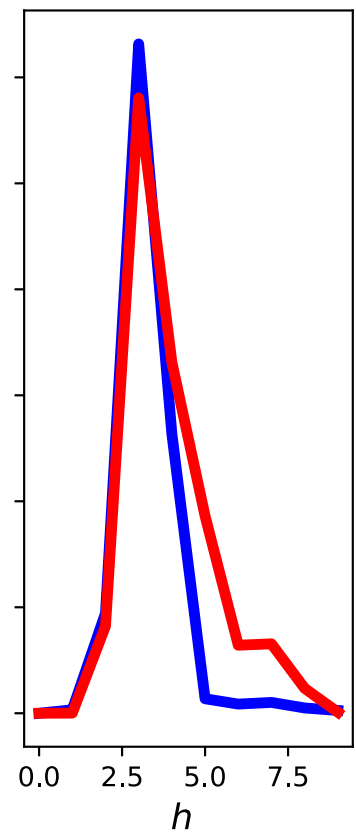

FIG. 3. Observed VARANAL (blue) and simulated (red) precipitation ( $\mathrm{mm} \mathrm{day}^{-1}$ ) on (a) 19 and (b) 20 Mar and (c) 7 and (d) 8 Sep 2014.

covering distance of $\Delta x$. This is attributed to weaker simulated updraft vertical velocities (as we discuss below) and smaller cloud volumes with finer grid resolution as also noted in Dawe and Austin (2011).

Entrainment profiles, however, start to converge at $500 \mathrm{~m}$ as the resolution gets coarser. As in-cloud vertical velocities retrieved from observations become available at convective scale, they provide an important constraint on the entrainment process, in which case the model's optimal performance appears to be at $1-\mathrm{km}$ resolution, as we discuss further in section $3 \mathrm{c}$.

\section{b. Entrainment in convective parameterization}

Early and recent attempts to estimate entrainment rate from observations and high-resolution model simulations utilized large-scale budget variables with (a)

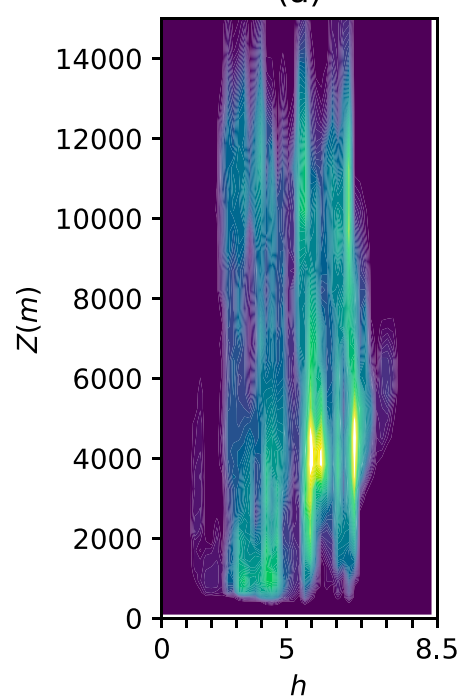

(b)

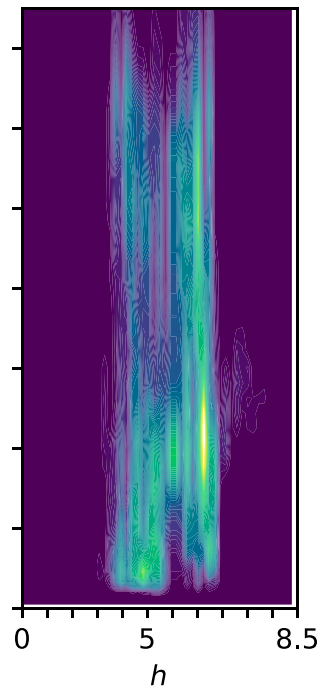

(c)

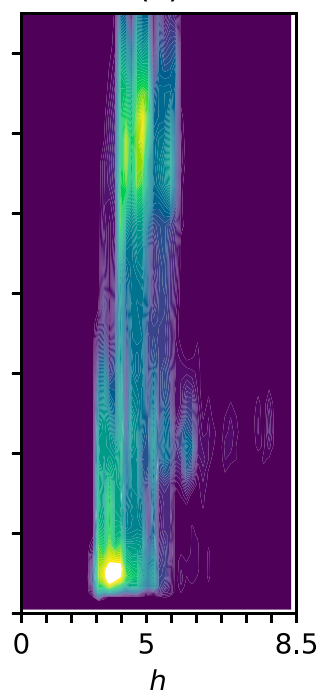

(d)

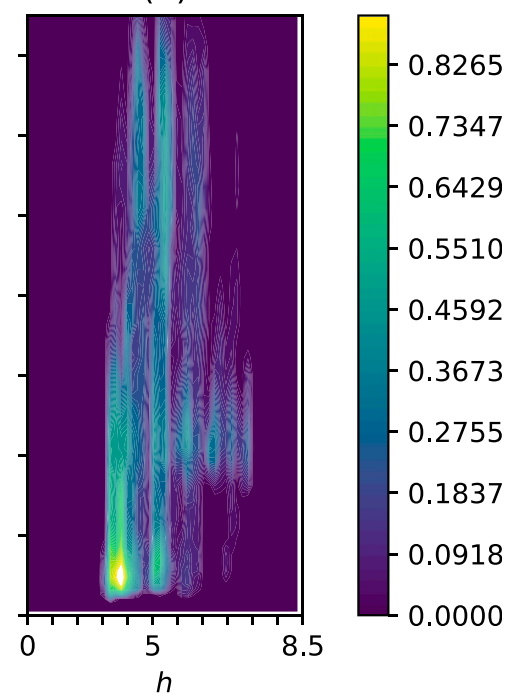

FIG. 4. Time evolution of the simulated convective-core air concentration $\Lambda\left(\mathrm{kg} \mathrm{m}^{-3}\right)$ on (a) 19 and (b) 20 Mar and (c) 7 and (d) 8 Sep 2014 at a model horizontal resolution of $1000 \mathrm{~m}$. 
(a) Net entrainment $(E-D)$

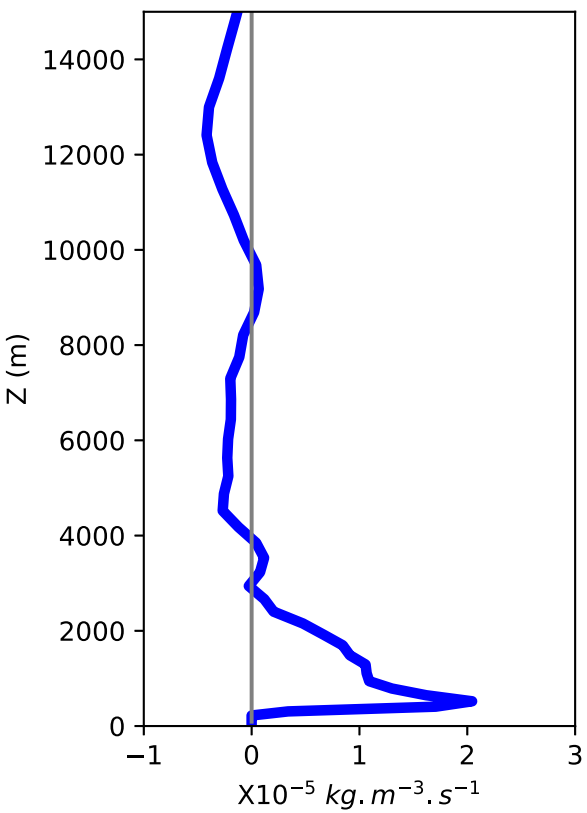

(b) entrainment/detrainment

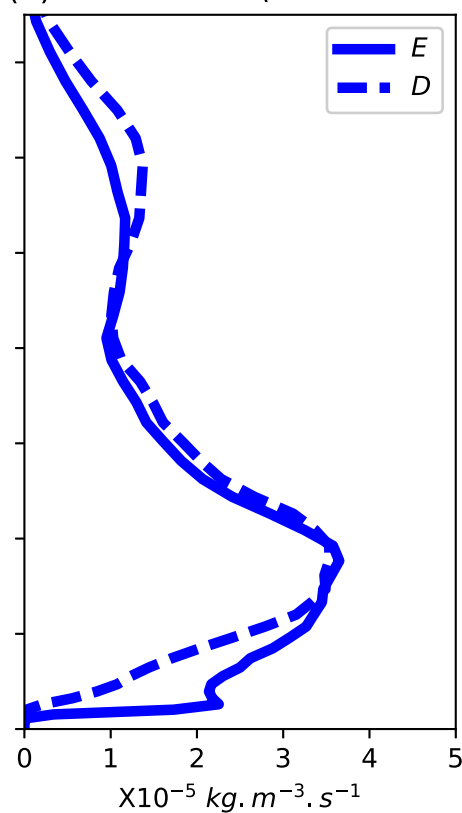

(c) rate

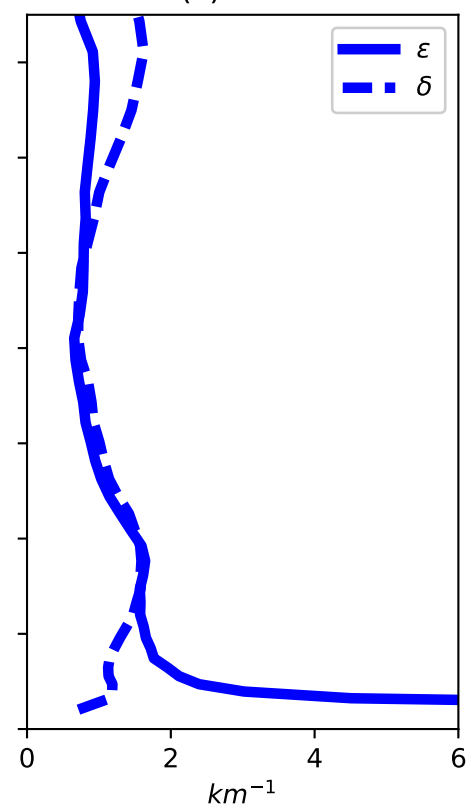

FIG. 5. Vertical profile of model-diagnosed (a) net entrainment $(E-D)$, (b) entrainment (solid) and detrainment (dashed), and (c) entrainment and detrainment rates.

conserved quantities such as moist static energy and equivalent potential temperature in an approach referred to as the bulk-plume model (e.g., Yanai et al. 1973; Tiedtke 1989; Siebesma et al. 2003; DelGenio and Wu 2010; de Rooy et al. 2013):

$$
\frac{d \theta_{e_{c}}}{d z}=\varepsilon_{\text {bulk-plume }}\left(\theta_{e_{E}}-\theta_{e_{c}}\right),
$$

where $\varepsilon_{\text {bulk-plume }}$ is the entrainment rate, $\theta_{e_{c}}$ and $\theta_{e_{E}}$ are equivalent potential temperatures in the convective cores as sampled in Eq. (1), and in the environment, respectively. This approach suffers from physical approximations rendering its relevance questionable. First, moist static energy [when used in Eq. (6)] relies on the hydrostatic approximation violating nonhydrostatic motions in convective clouds. Neither the moist static energy nor equivalent potential temperature is conserved for irreversible processes like diffusion and precipitation. In addition, this approach assumes that the entrained air is a mixture of cloudy and environment air and that the environment entrains its average properties into cloud plumes, which not only results in an underestimation of entrainment (e.g., Romps 2010, Zhang et al. 2016) but also a poor relationship with the diagnostic method one as shown in Fig. 7a.

Another approach in which entrainment is formulated as an explicit function of an environmental variable is one accounting for relative humidity $(\mathrm{RH})$, and used in a revised version of the ECMWF convective parameterization scheme (Bechtold et al. 2008):

$$
\varepsilon_{\text {Betchold }}=c_{0}\left(\frac{q_{s}}{q_{s b}}\right)^{2}+c_{1} \frac{q_{s}-q}{q}\left(\frac{q_{s}}{q_{s b}}\right)^{3},
$$

where $q, q_{s}$, and $q_{s b}$ are the specific humidity and saturation specific humidity at parcel and cloud-base level, respectively, and $c_{0}$ and $c_{1}$ are free parameters. Our model simulations of the Amazonian convection indicate that at high relative humidity (greater than 85\%) entrainment can span a wide range of values (Fig. $7 \mathrm{c}$ ).

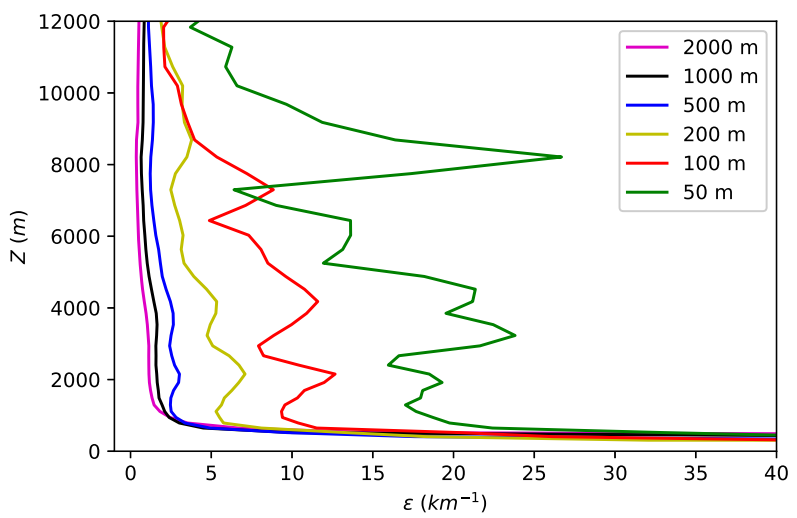

FIG. 6. Entrainment-rate dependence on model horizontal resolutions from $2 \mathrm{~km}$ to $50 \mathrm{~m}$. 


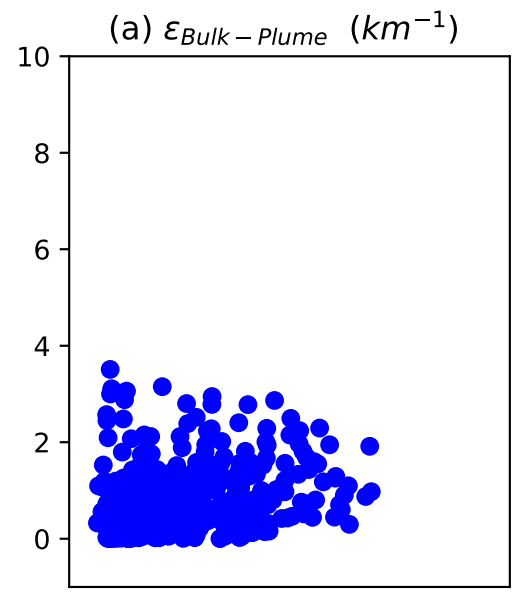

(d) $B\left(m \cdot s^{-2}\right)$

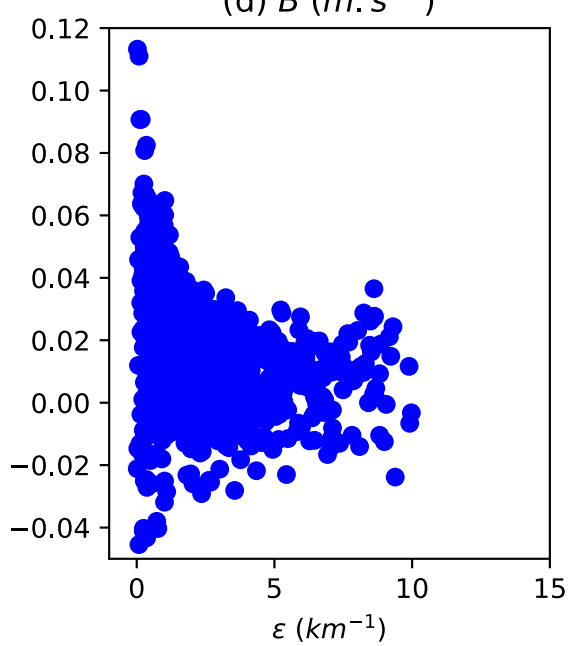

(b) $R H \quad(\%)$

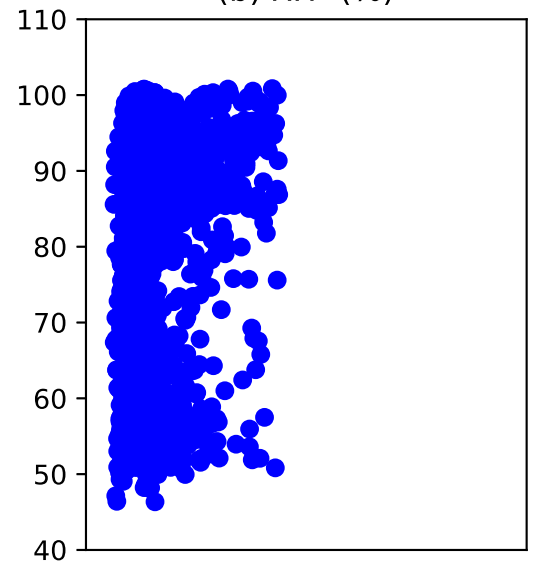

(e) $\varepsilon_{\text {Greg }}\left(\mathrm{km}^{-1}\right)$

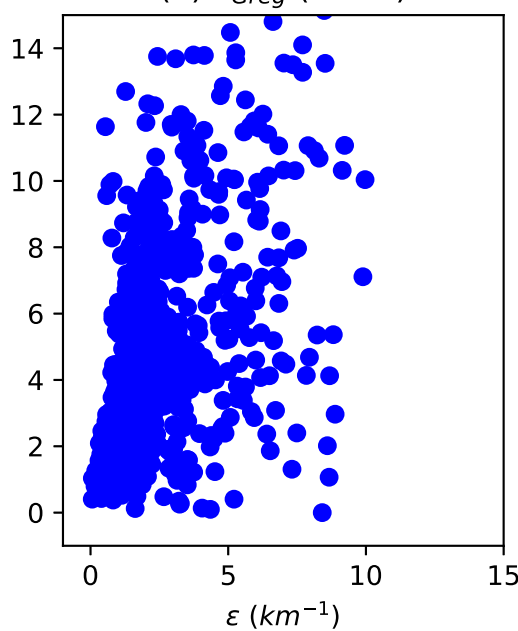

(c) $\varepsilon_{\text {Bechtold }}\left(\mathrm{km}^{-1}\right)$

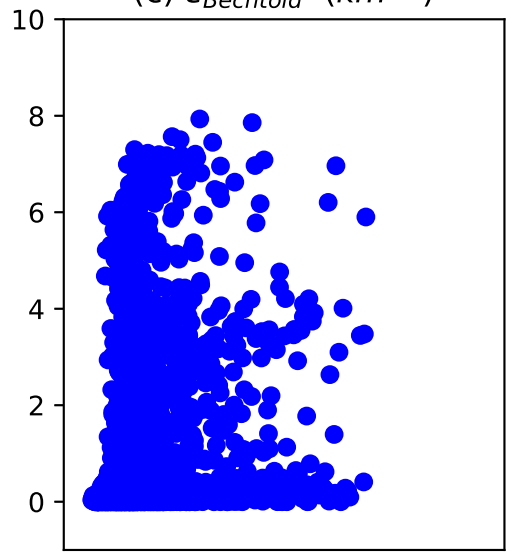

(f) $1 / w_{c}\left(s . m^{-1}\right)$

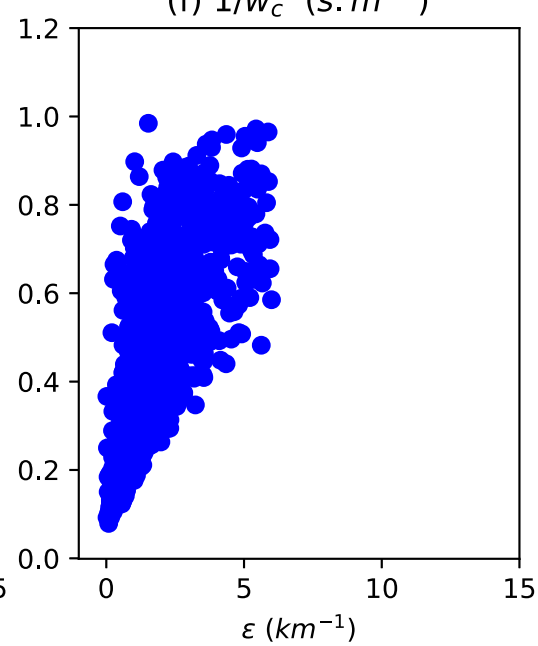

FIG. 7. Relationship between the model-diagnosed entrainment rate from GoAmazon simulations ( $x$ axis) and (a) estimated bulkplume entrainment using equivalent potential temperature, (b) relative humidity, (c) estimated entrainment rate using the Bechtold et al. (2008) empirical formula, (d) buoyancy, (e) estimated entrainment rate using the Gregory (2001) vertical velocity equation, and (f) inverse of updraft vertical velocity. The correlation coefficient for the latter relationship is 0.77 .

Moreover, vanishing magnitudes of entrainment can also span the whole RH spectrum as in Fig. 7b. This is further illustrated by contrasting the entrainment rate $\varepsilon_{\text {Betchold }}$ estimated using Eq. (7) above with the diagnosed one in Fig. 8a, where the dimensionless free parameters $c_{0}$ and $c_{1}$ are fitted to $3 \times 10^{-3}$ and $2 \times 10^{-2}$, respectively. The $\varepsilon_{\text {Betchold }}$ profile shows a rapid decrease with height, and vanishes above $8 \mathrm{~km}$. This is expected given its dependence on the cubed saturation specific humidity.

In an alternative approach, a number of studies (e.g., Bretherton and Smolarkiewicz 1989; Kain and Fritsch 1990; Lin 1999) suggested that the entrainment is inversely proportional to the parcel buoyancy (and its vertical gradient) in which negatively buoyant parcels detrain to the environment. This relationship, which has been adopted by a number of convective parameterization schemes (e.g., Emanuel and ŽivkovićRothman 1999; von Salzen and McFarlane 2002), is illustrated in Fig. $7 \mathrm{~d}$, where buoyancy is defined as $B=g\left(\theta_{v, c}-\overline{\theta_{v}}\right) / \overline{\theta_{v}}$, where $\theta_{v}=\theta\left(1+0.608 q_{v}-q_{l}\right)$ is the virtual potential temperature, $q_{v}$ and $q_{l}$ are the mass mixing ratio for water vapor and liquid water, respectively, $g$ is the gravitational acceleration, and the overbars denote horizontal averages. Overall the relationship, although exhibiting a linear trend, is weak, where less buoyant air becomes more susceptible to stronger entrainment, and negatively buoyant air (or previously detrained) can also be reentrained (Fig. 7d). These results agree with those in Romps (2010) for deep convection, though in Romps (2010) the relationship holds for shallow convection. 

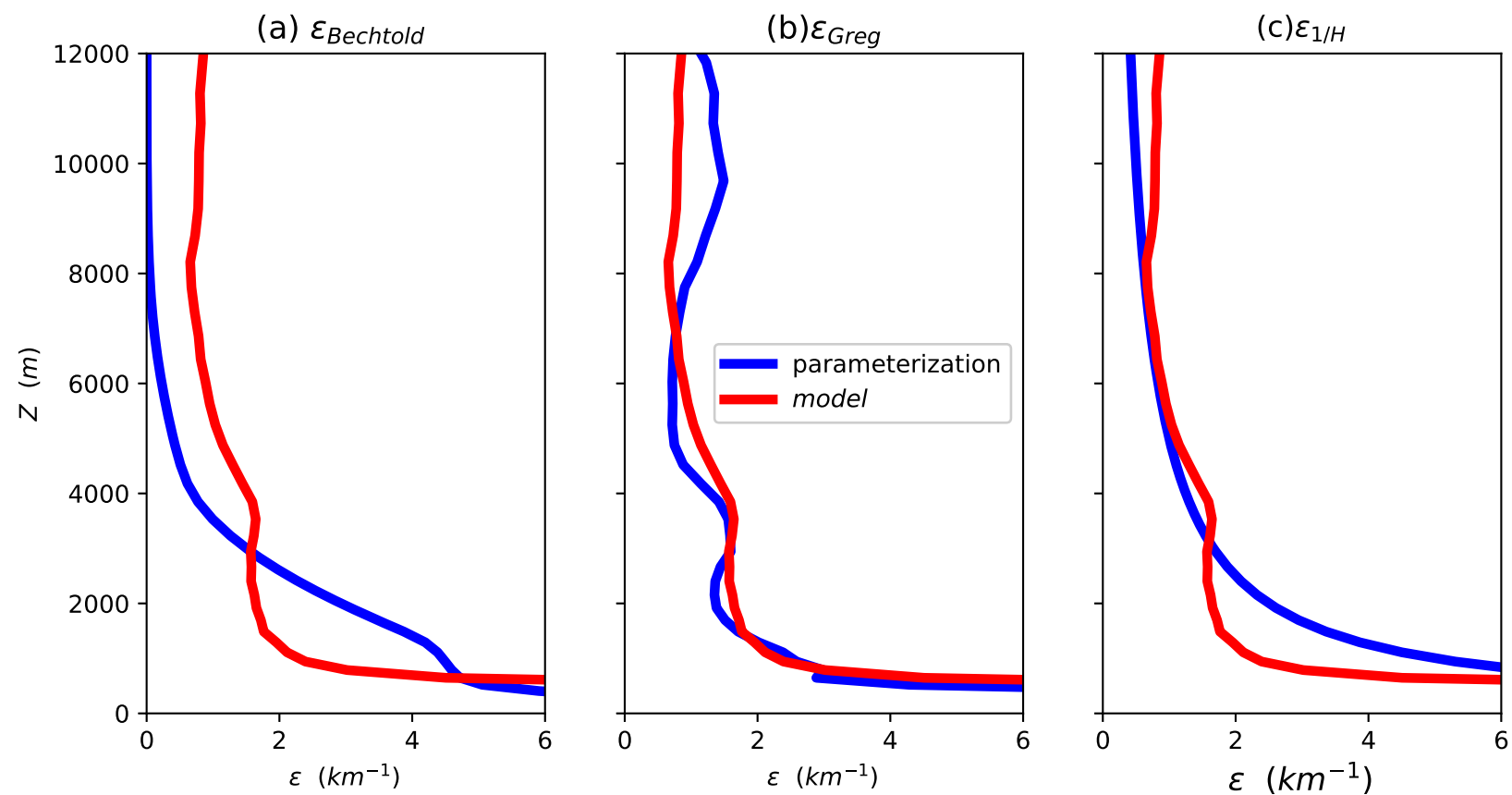

FIG. 8. Vertical profile of entrainment rate diagnosed from GoAmazon 2014/5 model simulations (red) and estimated (blue) using (a) Bechtold et al. (2008), (b) Gregory (2001), and (c) cloud-height parameterization.

Another expression that explicitly accounts for buoyancy and, yet, another important variable, which is the updraft vertical velocity (or its squared inverse), is the one proposed by Gregory (2001), and further encouraged by DelGenio and Wu (2010), and used in a number of convective schemes (e.g., Del Genio et al. 2007; Chikira and Sugiyama 2010; Kim et al. 2011):

$$
\varepsilon_{\mathrm{Greg}}=\beta \frac{B}{w_{c}^{2}},
$$

where $B$ is the buoyancy, $w_{c}$ is the convective updraft vertical velocity, and $\beta$ is free parameter. The illustrated linear relationship between the diagnosed entrainment and that estimated using Gregory method (Fig. 7e) is, to some extent, a good candidate, but becomes noisier at higher values. Attempting to construct a vertical profile of entrainment rate following Eq. (8), where dimensionless free parameter $\beta$ is fitted to $2 \times 10^{-4}$, results in an excellent match with the diagnostic method at lower levels below $4 \mathrm{~km}$ (Fig. 8b), but overestimation of entrainment at upper levels.

Finally Bretherton et al. (2004) formulated an entrainment rate that is inversely proportional to the height of the cumulus cloud, and used in convective parameterization (UWShCu) in Zhao et al. (2009, 2014):

$$
\varepsilon_{1 / H}=\frac{c}{H},
$$

where $H$ is the cloud-top height, and $c$ is a dimensionless free parameter. This formulation allows the cloud plumes to penetrate different heights depending on the shallow or deep convective regimes. While entrainment estimated from this method displays a good match with the diagnostic method at $5-8 \mathrm{~km}$ (here best fit $c=5$ ) it overestimates entrainment at lower levels and underestimates it above $8 \mathrm{~km}$ as in Fig. 8c. Overall the relationship between the diagnosed entrainment and that estimated from Eq. (9) is poor (not shown). This is because Eq. (9) assumes that the parcel termination height is inversely proportional to the entrainment rate, which might not be the case (e.g., Brast et al. 2016).

\section{c. Constraining entrainment with convective updraft velocities}

In addition to accurate observations, constraining the free parameters in the above formulations of entrainment rate requires well established physical relationships. It becomes obvious that the only robust relationship that stands out among those depicted in Fig. 7 is the one between the model-diagnosed entrainment rate and the inverse of the updraft vertical velocity in convective cores (Fig. 7f):

$$
\varepsilon_{\text {diagnosed }}=\gamma \frac{1}{w_{c}},
$$

where $\gamma$ is a constant. This relationship was first proposed by Neggers et al. (2002), and was tested in a 


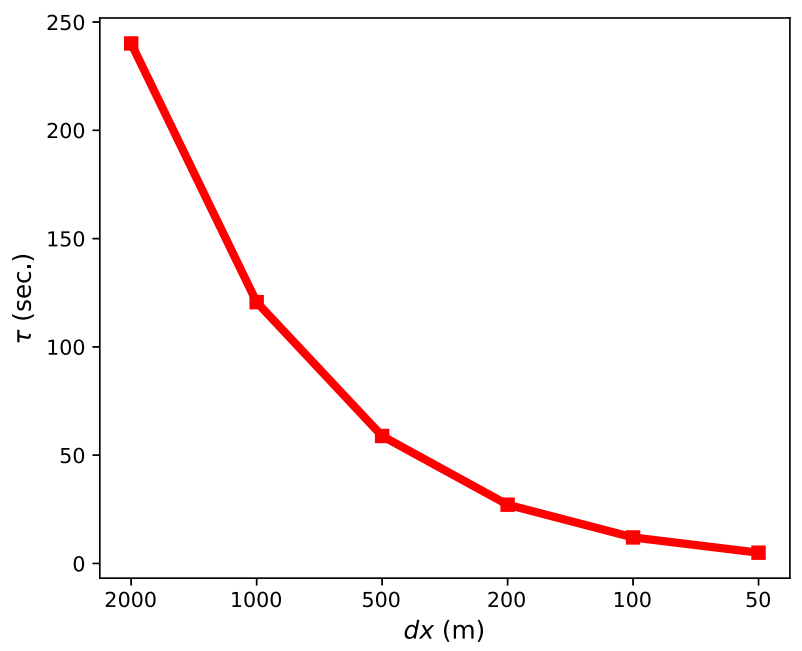

FIG. 9. Mixing time scale as a function of model horizontal resolution.

number of parameterization schemes for shallow (e.g., Lu et al. 2015) and deep convection (e.g., Del Genio and Wu 2010). Nordeng (1994) proposed a similar relationship but with $\gamma$ equal to the vertical gradient of updraft velocities. However, with the vertical gradient of updraft the relationship in Eq. (10) quickly degrades for both shallow and deep convection (de Rooy and Siebesma 2010) (not shown).

Here, we relax the vertical gradient of the updraft velocity to be a free parameter with units of inverse time, which can be determined from observations. The free parameter in this case is the inverse of mixing time scale (i.e., $\gamma=1 / \tau)$ : the time the environment takes to mix with convective clouds, or entrain into, the rising updraft. The relationship also holds robustly across different model resolutions with a (constant) mixing time scale that decreases monotonically from a few minutes to a few seconds as the horizontal resolution increases from cloud-system- to large-eddy-resolving (Fig. 9).

The choice of the mixing time scale can be inferred from observations contingent upon correctly simulating the updraft vertical velocity. The GoAmazon2014/5 field campaign collected an extended dataset of retrieved convective updraft velocities (Giangrande et al. 2016), enabling validation with model simulations across different resolutions. Given the native resolution of the $1290-\mathrm{MHz}$ radar wind profiler (approximately 10 -s temporal and $200-\mathrm{m}$ vertical resolutions, with an approximate beamwidth close to $500 \mathrm{~m}-1 \mathrm{~km}$ in the horizontal) an important RWP scale to consider is the one close to its native resolution near $1 \mathrm{~km}$ (Fig. 10a). It is not clear, however, why the model performs exceptionally well at this resolution and poorly at higher resolutions (Fig. 11). It is possible that the models' subgrid diffusion or turbulent mixing schemes could play a major role in modifying the strength of updraft velocities (e.g., Jeevanjee 2017; Anber et al. 2018).

Given the vertical dependence of updraft velocity [as also inferred from observational summaries for the Amazon found in Giangrande et al. (2016)], it is appropriate to estimate the vertical structure of the mixing
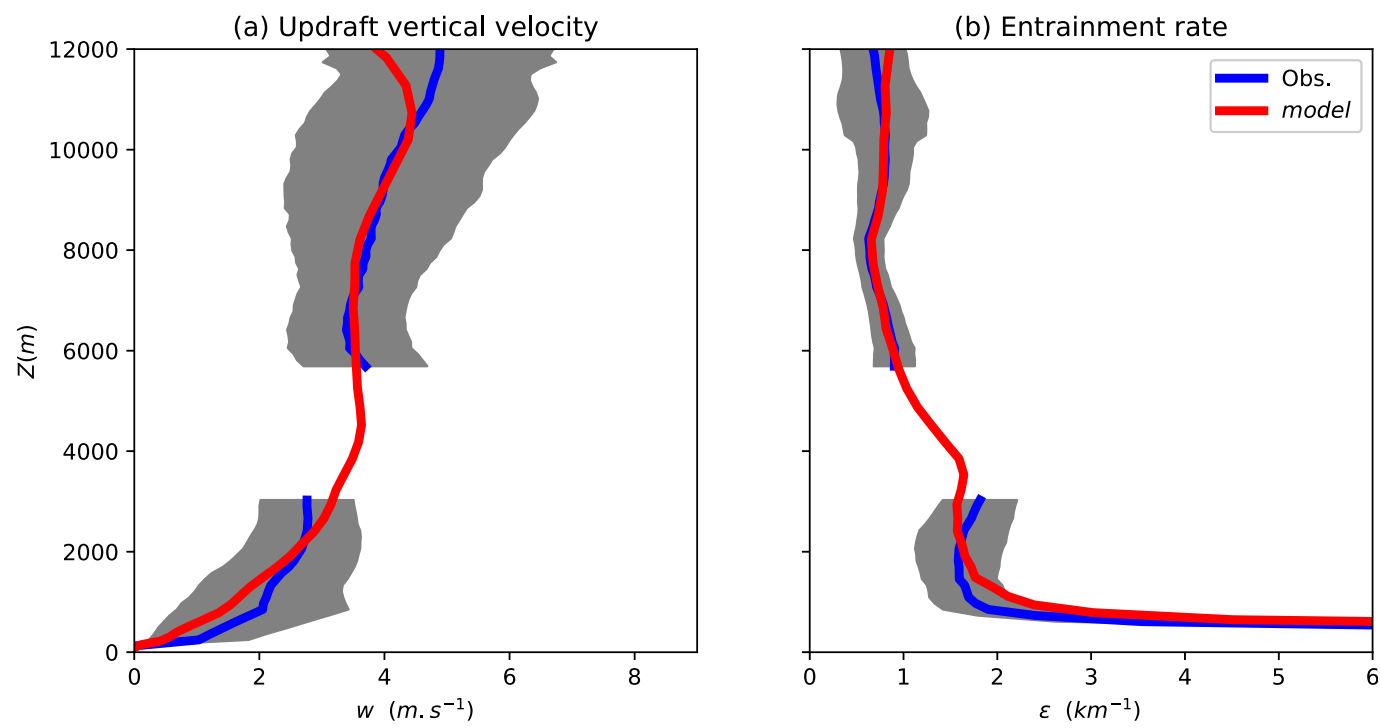

FIG. 10. Vertical profiles of (a) simulated updraft vertical velocities (red) at $d x=1 \mathrm{~km}$ and mean observed velocities (blue) and (b) model-diagnosed entrainment (red) and entrainment inferred from observed updraft velocities (blue) using Eq. (10). Shading represents plus and minus one standard deviation of the observed updrafts. 


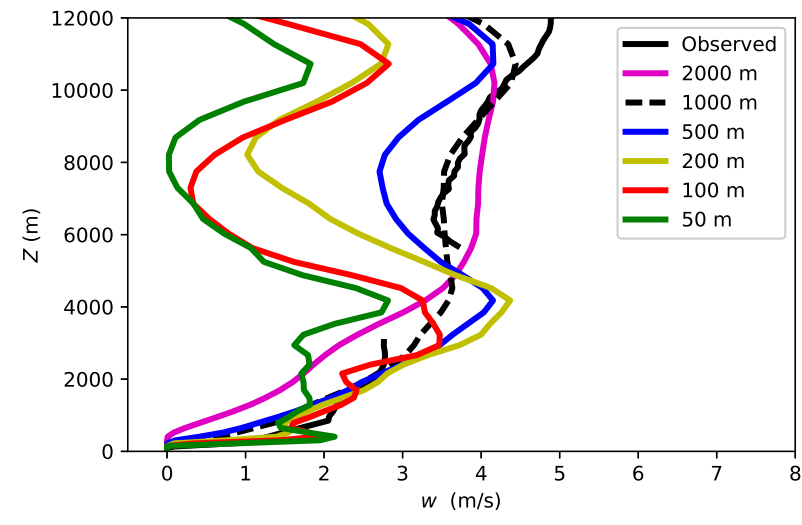

FIG. 11. Dependence of the simulated updraft vertical velocity in convective cores on the model's grid resolution from $2 \mathrm{~km}$ to $50 \mathrm{~m}$.

time scale from the model-diagnosed entrainment (Fig. 12). Above the cloud base where entrainment reaches a local minimum, mixing time scale attains a local maximum indicating a longer time taken by the environment to entrain into the updraft $(\sim 5 \mathrm{~min})$. This is a similar magnitude to the time scale estimated in Neggers et al. (2002) for shallow convection. When the entrainment reaches its local maxima near the freezing level, the time scale reaches minima (or fast mixing) before increasing again as the entrainment slightly decreases at $8 \mathrm{~km}$.

This estimation of the mixing time scale further facilitates a modified formulation of entrainment that closely matches $\varepsilon_{\text {diagnosed }}$ :

$$
\varepsilon_{1 / w_{c}}=\frac{1}{\tau(z)} \frac{1}{w_{c}} .
$$

The entrainment-rate profile $\varepsilon_{1 / w_{c}}$ shown in Fig. 10b as fitted using the observed vertical velocity with the estimated mixing time scale in Eq. (11) outperforms all other profiles used in parameterizations shown in Fig. 8, and illustrates the superiority of the updraft velocities over other environmental or cloud variables.

\section{Summary and discussion}

Despite the critical role the updraft vertical velocities play in entrainment and other atmospheric convective processes, they receive little attention in climate and numerical weather prediction models. Cloud-resolving models remain, in part, unreliable in their prognostic vertical velocities because of the lack of observed updraft velocities. Here, cloud-resolving model simulations of four deep convective precipitating events over the Amazon basin were performed to diagnose the entrainment- and detrainment-rate profiles. The model is forced by the observed large-scale winds and

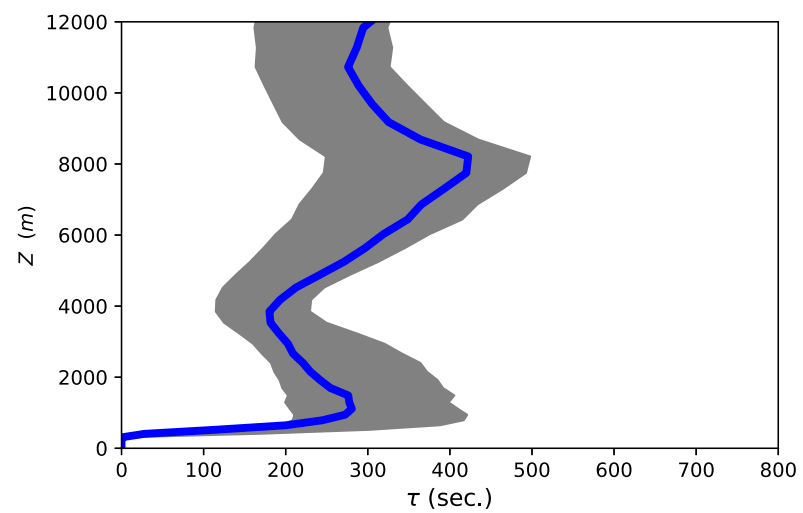

FIG. 12. Vertical dependency of the mixing time scale using the observed vertical velocities. Shading represents plus and minus one standard deviation of the estimated time scale.

temperature, and surface latent and heat fluxes derived from the GoAmazon 2014/5 field campaign.

Entrainment and detrainment are computed by applying the mass conservation to the cloud convective cores and accounting from the mass sources and sinks into the cores across the clouds interface. When environmental air intrudes into the convective core, cloud volume shrinks and the process counts as entrainment, and when a cloudy grid cell leaves the convectivecore cloud volume expands and the process counts as detrainment.

The model-diagnosed entrainment exhibits a robust linear relationship with the inverse of the updraft vertical velocities in convective cores. This relationship surpasses others with environmental thermodynamic or cloud variables such as relative humidity and buoyancy, respectively, and qualifies the updraft vertical velocity as a leading candidate to formulate entrainment rate. Although, our diagnostic method tends to overestimate entrainment/detrainment compared to the one accounting for subgrid-scale changes in the cloud volume (e.g., Dawe and Austin 2011), the observed updraft velocities from the RWP exhibit strong constrains on the diagnosed entrainment. The strong correlation between entrainment and the inverse of the convective updraft velocities does not seem to be dependent on the model resolution. Therefore, a model resolution at which the simulated convective updraft velocities closely match the observed velocities can also serve to dynamically diagnose the entrainment process. Here, a resolution near $1 \mathrm{~km}$ grants this match as a result of, in part, being similar to the beamwidth of the radar profiler itself. The correlation coefficient resulting from the above relationship provides an estimation for the mixing time scale, which defines the time scale the environment takes to interrupt the convective cores on average. 
Our results here concur with other studies that relate the entrainment rates to the updraft velocities (e.g., Neggers et al. 2002; Lu et al. 2015; Zhang et al. 2016). In particular, Zhang et al. (2016) estimated entrainment rates using a $1-\mathrm{km}$ resolution cloud-resolving model (CRM) simulation of convective clouds from the Tropical Warm Pool-International Cloud Experiment (TWP-ICE) using the moist static energy budget, and showed the rates were best fitted to the inverse of in-cloud vertical velocity by a second-order polynomial. Moreover, their analyses resulted in two different fitting coefficients between the upper and lower troposphere, suggesting a vertical dependency in which we reconcile here using a variable mixing time scale.

Since global climate models are unlikely to operate at nonhydrostatic cloud-resolving resolution in the near future, it remains for the modeling community to test the hypothesis developed here, and find empirical methods to calibrate the observed updraft vertical velocities in GCMs. The findings in our study encourage long-term and global coverage deployment of instruments to reliably gather long-time series of the updraft velocities over different convective regimes in order to better explore their behavior and relationship with the large-scale environments, and likely to constrain climate forcing and sensitivity.

Acknowledgments. This work supported by the U.S. Department of Energy's Office of Science, Biological and Environmental Research via the Atmospheric System Research (ASR) Program under Contract DESC0012704. The publisher, by accepting the paper for publication, acknowledges that the U.S. Government retains a nonexclusive, paid-up, irrevocable, worldwide license to publish or reproduce the published form of this paper, or allow others to do so, for U.S. Government purposes. We also acknowledge the Atmospheric Radiation Measurement (ARM) Climate Research Facility, a user facility of the U.S. DOE, Office of Science, sponsored by the Office of Biological and Environmental Research, and support from the ASR program of that office. Special thanks to David Romps for useful discussion on implementing the diagnostic method. Thanks to Shuguang Wang for providing support on model setup, Nadir Jeevanjee and Chuck Seman for serving as internal reviewers from Princeton/GFDL. This work was supported by resources provided by the Scientific Data and Computing Center (SDCC), a component of the Computational Science Initiative (CSI) at Brookhaven National Laboratory (BNL). The program code for the simulations, based on the Weather Research and Forecasting (WRF) Model, is publicly available online (http://www2.mmm.ucar.edu/wrf/users/ model.html). All ARM datasets used for this study may be downloaded from the ARM website (http:// www.arm.gov; e.g., Martin et al. 2014).

\section{REFERENCES}

Anber, U., N. Jeevanjee, L. M. Harris, and I. M. Held, 2018: Sensitivity of radiative-convection equilibrium to divergence damping in GFDL-FV3-based cloud-resolving model. J. Adv. Model. Earth Syst., 10, 1527-1536, https://doi.org/10.1029/ 2017MS001225.

Bechtold, P., M. Kohler, T. Jung, F. Doblas-Reyes, M. Leutbecher, M. J. Rodwell, F. Vitart, and G. Balsamo, 2008: Advances in simulating atmospheric variability with the ECMWF model: From synoptic to decadal time-scales. Quart. J. Roy. Meteor. Soc., 134, 1337-1351, https://doi.org/10.1002/qj.289.

Brast, M., R. A. J. Neggers, and T. Heus, 2016: What determines the fate of rising parcels in a heterogeneous environment? J. Adv. Model. Earth Syst., 8, 1674-1690, https://doi.org/ 10.1002/2016MS000750.

Bretherton, C. S., and P. K. Smolarkiewicz, 1989: Gravity waves, compensating subsidence and detrainment around cumulus clouds. J. Atmos. Sci., 46, 740-759, https://doi.org/10.1175/ 1520-0469(1989)046<0740:GWCSAD>2.0.CO;2.

_, J. R. McCaa, and H. Grenier, 2004: A new parameterization for shallow cumulus convection and its application to marine subtropical cloud-topped boundary layers. Part I: Description and 1D results. Mon. Wea. Rev., 132, 864-882, https://doi.org/ 10.1175/1520-0493(2004)132<0864:ANPFSC >2.0.CO;2.

Chikira, M., and M. Sugiyama, 2010: A cumulus parameterization with state-dependent entrainment rate. Part I: Description and sensitivity to temperature and humidity profiles. J. Atmos. Sci., 67, 2171-2193, https://doi.org/10.1175/2010JAS3316.1.

Dawe, J. T., and P. H. Austin, 2011: Interpolation of LES cloud surfaces for use in direct calculations of entrainment and detrainment. Mon. Wea. Rev., 139, 444-456, https://doi.org/ 10.1175/2010MWR3473.1.

de Rooy, W. C., and A. P. Siebesma, 2010: Analytical expressions for entrainment and detrainment in cumulus convection. Quart. J. Roy. Meteor. Soc., 136, 1216-1227, https://doi.org/ 10.1002/qj.640.

— mulus convection: An overview. Quart. J. Roy. Meteor. Soc., 139, 1-19, https://doi.org/10.1002/qj.1959.

Del Genio, A. D., and J. Wu, 2010: The role of entrainment in the diurnal cycle of continental convection. J. Atmos. Sci., 23, 2722-2738, https://doi.org/10.1175/2009JCLI3340.1.

—, M.-S. Yao, and J. Jonas, 2007: Will moist convection be stronger in a warmer climate? Geophys. Res. Lett., 34, L16703, https://doi.org/10.1029/2007GL030525.

Donner, L. J., T. A. O'Brien, D. Rieger, B. Vogel, and W. F. Cooke, 2016: Are atmospheric updrafts a key to unlocking climate forcing and sensitivity? Atmos. Chem. Phys., 16, 12 983-12 992, https://doi.org/10.5194/acp-16-12983-2016.

Emanuel, K., and M. Živković-Rothman, 1999: Development and evaluation of a convection scheme for use in climate models. J. Atmos. Sci., 56, 1766-1782, https://doi.org/10.1175/15200469(1999)056<1766:DAEOAC > 2.0.CO;2.

Giangrande, S. E., and Coauthors, 2016: Convective cloud vertical velocity and mass-flux characteristics from radar wind profiler observations during GoAmazon2014/5. J. Geophys. 
Res. Atmos., 121, 12 891-12 913, https://doi.org/10.1002/ 2016JD025303.

Gregory, D., 2001: Estimation of entrainment rate in simple models of convective clouds. Quart. J. Roy. Meteor. Soc., 127, 53-72, https://doi.org/10.1002/qj.49712757104.

Jeevanjee, N., 2017: Vertical velocity in the gray zone. $J . A d v$ Model. Earth Syst., 9 2304-2316, https://doi.org/10.1002/ 2017MS001059.

Kain, J., and J. Fritsch, 1990: A one-dimensional entraining/ detraining plume model and its application in convective parameterization. J. Atmos. Sci., 47, 2784-2802, https://doi.org/ 10.1175/1520-0469(1990)047<2784:AODEPM>2.0.CO;2.

Kim, D., A. H. Sobel, A. D. Del Genio, Y. Chen, S. J. Camargo, M.-S. Yao, M. Kelley, and L. Nazarenko, 2011: The tropical subseasonal variability simulated in the NASA GISS general circulation model. J. Atmos. Sci., 25, 4641-4659, https:// doi.org/10.1175/JCLI-D-11-00447.1.

Klemp, J. B., J. Dudhia, and A. Hassiotis, 2008: An upper gravitywave absorbing layer for NWP applications. Mon. Wea. Rev., 136, 3987-4004, https://doi.org/10.1175/2008MWR2596.1.

Klocke, D., R. Pincus, and J. Quaas, 2011: On constraining estimates of climate sensitivity with present-day observations through model weighting. J. Climate, 24, 6092-6099, https:// doi.org/10.1175/2011JCLI4193.1.

Lin, C., 1999: Some bulk properties of cumulus ensembles simulated by a cloud-resolving model. Part II: Entrainment profiles. J. Atmos. Sci., 56, 3736-3748, https://doi.org/10.1175/ 1520-0469(1999)056<3736:SBPOCE $>2.0 . \mathrm{CO} ; 2$.

Long, C., K. Gaustad, and L. Riihimaki, 1994: Radiative flux analysis (RADFLUX1LONG), 3.21297 S, $60.5981 \mathrm{~W}$ : ARM Mobile Facility (MAO) Manacapuru, Amazonas, Brazil; AMF1 (M1) (updated hourly). ARM Climate Research Facility Data Archive. Subset used: 15 February-10 October 2014, accessed 9 March 2016, https://doi.org/10.5439/1179822.

Lu, C., Y. Liu, G. J. Zhang, X. Wu, S. Endo, L. Cao, Y. Li, and X. Gao, 2015: Improving parameterization of entrainment rate for shallow convection with aircraft measurements and large-eddy simulation. J. Atmos. Sci., 73, 761-773, https:// doi.org/10.1175/JAS-D-15-0050.1.

Martin, S., and Coauthors, 2014: Campaign datasets for Observations and Modeling of the Green Ocean Amazon (GOAMAZON), 3.1190 S, 60.0217 W: Gulfstream 159 aircraft (F1) (updated per flights). ARM Data Archive. Subset used: January-October 2014, accessed 30 May 2016, https://doi.org/10.5439/1346559.

- , and Coauthors, 2016: Introduction: Observations and modeling of the Green Ocean Amazon (GoAmazon2014/5). Atmos. Chem. Phys., 16, 4785-4797, https://doi.org/10.5194/acp16-4785-2016.

—_ and Coauthors, 2017: The Green Ocean Amazon Experiment (GoAmazon2014/5) observes pollution affecting gases, aerosols and clouds over the Amazon rain forest. Bull. Amer. Meteor. Soc., 98, 981-997, https://doi.org/10.1175/BAMS-D15-00221.1.

McCoy, R., Y. Zhang, and S. Xie, 2003: Quality controlled eddy correlation flux measurement (30QCECOR), $3.21297 \mathrm{~S}$ 60.5981 W: ARM Mobile Facility (MAO) Manacapuru, Amazonas, Brazil; AMF1 (M1) (updated hourly). ARM Climate Research Facility Data Archive. Subset used: 15 February-10 October 2014, accessed 22 March 2016, https://doi.org/ $10.5439 / 1097546$.

Morrison, H., J. A. Curry, and V. I. Khvorostyanov, 2005: A new double-moment microphysics scheme for application in cloud and climate models. Part I: Description. J. Atmos. Sci., 62, 1665-1677, https://doi.org/10.1175/JAS3446.1.

Neggers, R., A. Siebesma, and H. Jonker, 2002: A multiparcel method for shallow cumulus convection. J. Atmos. Sci., 59, 1655-1668, https://doi.org/10.1175/1520-0469(2002)059<1655: AMMFSC $>2.0 . \mathrm{CO} ; 2$.

Nordeng, T. E., 1994: Extended versions of the convection parametrization scheme at ECMWF and their impact upon the mean climate and transient activity of the model in the tropics. ECMWF Tech. Memo. 206, 41 pp., https://www.ecmwf.int/sites/ default/files/library/1994/11393-extended-versions-convectiveparametrization-scheme-ecmwf-and-their-impact-mean-andtransient.pdf.

Park, S., and C. S. Bretherton, 2009: The University of Washington shallow convection and moist turbulence schemes and their impact on climate simulations with the Community Atmosphere Model. J. Climate, 22, 3449-3469, https://doi.org/ 10.1175/2008JCLI2557.1.

Romps, D. M., 2010: A direct measurement of entrainment. J. Atmos. Sci., 67, 1908-1927, https://doi.org/10.1175/2010JAS3371.1.

Rougier, J., D. Sexton, J. Murphy, and D. Stainforth, 2009: Analyzing the climate sensitivity of the HadSM3 climate model using ensembles from different but related experiments. J. Climate, 22, 3540-3557, https://doi.org/10.1175/2008JCLI2533.1.

Sanderson, B. M., K. Shell, and W. Ingram, 2010: Climate feedbacks determined using radiative kernels in a multi-thousandmember ensemble of AOGCMs. Climate Dyn., 35, 1219-1236, https://doi.org/10.1007/s00382-009-0661-1.

Sherwood, S., S. Bony, and J.-L. Dufresne, 2014: Spread in model climate sensitivity traced to atmospheric convective mixing. Nature, 505, 37-42, https://doi.org/10.1038/nature12829.

Siebesma, A., and Coauthors, 2003: A large eddy simulation intercomparison study of shallow cumulus convection. J. Atmos. Sci., 60, 1201-1219, https://doi.org/10.1175/1520-0469(2003) $60<1201$ :ALESIS $>2.0 . \mathrm{CO} ; 2$

Skamarock, W. C., and Coauthors, 2008: A description of the Advanced Research WRF version 3. NCAR Tech. Note NCAR/TN-475+STR, 113 pp., https://doi.org/10.5065/ D68S4MVH.

Stainforth, D., and Coauthors, 2005: Uncertainty in predictions of the climate response to rising levels of greenhouse gases. Nature, 433, 403-406, https://doi.org/10.1038/nature03301.

Su, H., J. Jiang, C. Zhai, J. Shen, J. Neelin, G. Stephens, and Y. Yung, 2014: Weakening and strengthening structures in the Hadley circulation change under global warming and implications for cloud response and climate sensitivity. J. Geophys. Res. Atmos., 119, 5787-5805, https://doi.org/10.1002/ 2014JD021642.

Tang, S., S. Xie, and Y. Zhang, 2001: Atmospheric Radiation Measurement Climate Research Facility SCM forcing data from variational analysis (VARANAL), $3.21297 \mathrm{~S} 60.5981 \mathrm{~W}$ : ARM Mobile Facility (MAO) Manacapuru, Amazonas, Brazil; AMF1 (M1) (updated monthly). Atmospheric Radiation Measurement Climate Research Facility Data Archive. Subset used: 1 January 2014-31 December 2015, accessed 22 July 2016, https://doi.org/10.5439/1273323.

and Coauthors, 2016: Large-scale structure and diabatic heating and drying profiles associated with seasonal and diurnal variations of convective systems observed in GoAmazon 2014/5 experiment. Atmos. Chem. Phys., 16, 14 249-14264, https://doi.org/10.5194/acp-16-14249-2016.

Tiedtke, M., 1989: A comprehensive mass flux scheme for cumulus parameterization in large-scale models. Mon. Wea. Rev., 117, 
1779-1800, https://doi.org/10.1175/1520-0493(1989)117<1779: ACMFSF $>2.0 . \mathrm{CO} ; 2$.

von Salzen, K., and N. A. McFarlane, 2002: Parameterization of the bulk effects of lateral and cloud-top entrainment in transient shallow cumulus clouds. J. Atmos. Sci., 59, 1405-1430, https://doi.org/10.1175/1520-0469(2002)059<1405: POTBEO > 2.0.CO;2.

Yanai, M., S. Esbensen, and J.-H. Chu, 1973: Determination of bulk properties of tropical cloud clusters from large-scale heat and moisture budgets. J. Atmos. Sci., 30, 611-627, https://doi.org/10.1175/1520-0469(1973)030<0611:DOBPOT> 2.0.CO;2.

Zelinka, M., S. Klein, and D. Hartmann, 2012: Computing and partitioning cloud feedbacks using cloud property histograms: Part I. Cloud radiative kernels. J. Climate, 25, 3715-3735, https://doi.org/10.1175/JCLI-D-11-00248.1.
Zhang, G., X. Wu, X. Zeng, and T. Mitovski, 2016: Estimation of convective entrainment properties from a cloud-resolving model simulation during TWP-ICE. Climate Dyn., 47, 21772192, https://doi.org/10.1007/s00382-015-2957-7.

Zhao, M., 2014: An investigation of the connections among convection, clouds, and climate sensitivity in a global climate model. J. Climate, 27, 1845-1862, https://doi.org/10.1175/ JCLI-D-13-00145.1.

—_, I. M. Held, S.-J. Lin, and G. A. Vecchi, 2009: Simulations of global hurricane climatology, interannual variability, and response to global warming using a $50-\mathrm{km}$ resolution GCM. J. Climate, 22, 6653-6678, https://doi.org/10.1175/ 2009JCLI3049.1.

,$- \ldots$, and - 2012: Some counterintuitive dependencies of tropical cyclone frequency on parameters in a GCM. J. Atmos. Sci., 69, 2272-2283, https://doi.org/10.1175/JAS-D-11-0238.1. 